\title{
REPRESENTACIÓN CARTOGRÁFICA DE LOS ASENTAMIENTOS HUMANOS EN LOS MAPAS DE ANDALUCÍA DE LOS SIGLOS XVI-XVIII
}

\author{
José Carlos Posada Simeón \\ Universidad de Sevilla \\ posada@us.es \\ ORCID iD: https://orcid.org/0000-0002-9386-163X
}

Recibido: 24/04/2019; Aceptado: 08/10/2019.

\begin{abstract}
Cómo citar este artículo/Citation: Posada Simeón, J. C. (2019). Representación cartográfica de los asentamientos humanos en los mapas de Andalucía de los siglos XVI-XVIII. Estudios Geográficos, 80 (287), e025. https://doi.org/10.3989/estgeogr.201942.022

RESUMEN: Entre los símbolos cartográficos más utilizados a lo largo de la historia destacan los que representan los asentamientos humanos. Se plantea en este estudio analizar estos elementos en los mapas de la Edad Moderna a una escala regional y que tenga como territorio a Andalucía. Se establece una tipología de signos basada en cinco atributos: complejidad (realista - esquemático), puntos de vista (alzado - planta), composición (figurativo - geométrico), naturaleza del mapa (administración civil, administración eclesiástica y náutica) y la jerarquía de los signos (esquematización y abstracción).
\end{abstract}

PALABRAS CLAVE: Semiología; Signos cartográficos; Asentamientos; Cartografía regional; Renacimiento; historia de la cartografía.

\section{CARTOGRAPHIC REPRESENTATION OF HUMAN SETTLEMENTS IN THE ANDALUSIAN MAPS OF THE XVI-XVIII CENTURIES}

ABSTRACT: Among the most used cartographic symbols throughout history, those that represent human settlements stand out. It is proposed in this study to analyze these elements in the maps of the Modern Age on a regional scale and that has Andalusia as its territory. A typology of signs is established based on five attributes: complexity (realistic - schematic), points of view (elevation - plan), composition (figurative - geometric), nature of the map (civil administration, ecclesiastical administration and nautical) and hierarchy of the signs (schematization and abstraction).

KEY WORDS: Semiology; Cartographic signs; Settlements; Regional cartography; Renaissance; History of cartography. 


\section{INTRODUCCIÓN}

Uno de los principales elementos representados cartográficamente a lo largo de la historia ha sido los núcleos de población. La preocupación por dibujarlos desde diferentes perspectivas se remonta incluso a la antigüedad clásica. En los Itineraria Picta romanos, fundamentalmente en la Tabulae Peutigeriana, se ilustraban las poblaciones más importantes, tanto en alzado como en perspectiva caballera, junto con las vías de comunicación que las unían. En la Edad Media también se realizaron mapas donde las localizaciones de las ciudades más importantes estaban ilustradas profusamente e iluminadas con diversos colores (mapamundi de Hereford o el de Ebsfort). Igualmente, en la cultura islámica aparecieron mapas con este tipo de signos siendo uno de los más conocidos el de Al Idrisi de 1154. En este caso, en su Tabula Rogeriana, estos asentamientos estaban simbolizados por rosetas o círculos segmentados (Posada, 2011, p. 170). Con la aparición de los portulanos, los núcleos de población, principalmente los costeros, fueron representados de manera mucho más simple llegando incluso a ser sustituidos por su propio topónimo. La simbolización de estas poblaciones no era necesaria ya que el objetivo principal de estos mapas consistía en el establecimiento de rumbos para la navegación.

La proliferación de mapas en la era de los descubrimientos condujo a que se dibujaran de múltiples modos los asentamientos humanos. Esta característica fue especialmente relevante en los mapas regionales y más concretamente, como es el caso que nos ocupa, en el territorio andaluz. Las representaciones de los núcleos de población, como comprobaremos a lo largo de este estudio, han variado tanto en su complejidad, puntos de vista, composición o naturaleza como por la jerarquía de los signos cartográficos empleados.

\section{OBJETIVOS Y METOdologíA}

El objetivo principal de este artículo es examinar semiológicamente los mapas regionales de Andalucía en la Edad Moderna para comprobar cómo se representan los núcleos de población y a qué criterios obedecen. Para conseguir este objetivo se han analizado aquellos mapas publicados entre los siglos XVI y XVIII, y que han tenido como territorio principal cartografiado a Andalucía, aunque no sea en su totalidad. Esta manera de proceder, la de observar un mismo territorio a lo largo del tiempo, nos permite identificar las particularidades de los diseños semiológicos adoptados para la ilustración de los asentamientos. Además, esta representación debe fundamentarse en la nece- sidad de un código simbólico, un icono, basado en la comprensión de la lógica gráfica (Bertín, 1973, p. 426) y en las limitaciones de la percepción visual (Monmonier, 1991, p. 19) que nos restringe la apreciación de los detalles de un signo.

El proceso metodológico utilizado ha sido en primer lugar el de identificar qué mapas fueron los más significativos desde la perspectiva tipológica de signos empleados. Se realizó, para ello, una selección de 48 mapas que explicaran toda la diversidad de representación de los asentamientos humanos en Andalucía, excluyendo aquellos que utilizaban los mismos signos que los que aparecían en otros mapas precedentes, sin ningún aporte propio, en muchas ocasiones por el uso de la misma plancha de grabado. También se descartaron aquellos otros sin ningún valor específico en las ilustraciones de los núcleos urbanos. Entre los excluidos podemos citar el Mapa de la Jurisdición de los Reinos de Granada y Murcia de Isidro Próspero de Verboom de 1721, el de Juan de Medrano y Corella de 1743 denominado El obispado de Málaga dividido en sus siete vicarías... (a pesar del título el mapa abarca desde Cádiz a Murcia), o el Mapa que comprende la provincia antigua de la Bética de Juan López de 1788, entre otros.

De todos los mapas seleccionados, y referenciados al final del artículo, 6 son manuscritos y 42 impresos. El rango de escala para estos últimos varía desde ca. 1:350.000 (Salcedo de Aguirre, 1587) hasta ca. 1:3.003.000 (Van der Aa, 1714). Para la cartografía manuscrita esta horquilla es menor, oscilando entre ca. 1:345.000 (Eguilart, 1770) hasta ca. 1:1.760.000 (Espelius, 1765).

Una vez seleccionados se ha llevado a cabo una clasificación, comparación e investigación de estos mapas, siguiendo esta metodología que es una de las más utilizadas en la cartografía antigua (Woodward, 2007b, p. 607; San Antonio, 2006, p. 3; Cortese y Membribe, 2008, p. 355). Esta forma de proceder nos suministra las herramientas necesarias para constituir una tipología de signos de los núcleos de población, enmarcándola en su contexto espacio- temporal, ya que es la única forma de interpretarlos (Harley, 2002, p. 167). Este análisis contextual también nos permite contrastar los diferentes mapas y no entenderlos como objetos singulares (Stone, 2005, p. 291; Mendoza y Lois, 2009, p. 15). Así, podemos establecer unos patrones de signos que se mantienen en el tiempo y entre diferentes cartógrafos y, simultáneamente, otros que no se rigen por ningún tipo de estándares (Delano, 2007, p. 538), rasgo propio del espíritu individualista de la Edad Moderna. 
FIGURA 1

METODOLOGÍA EMPLEADA PARA EL ESTUDIO DE LOS SIGNOS CARTÓGRÁFICOS DE LOS NÚCLEOS DE POBLACIÓN

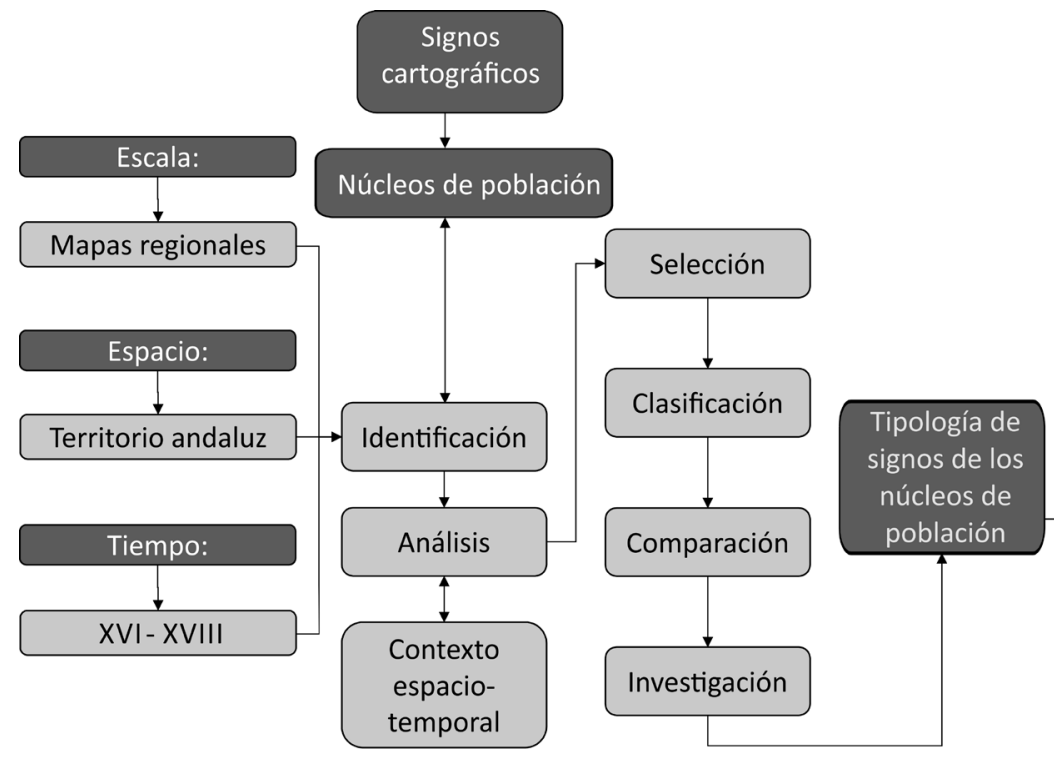

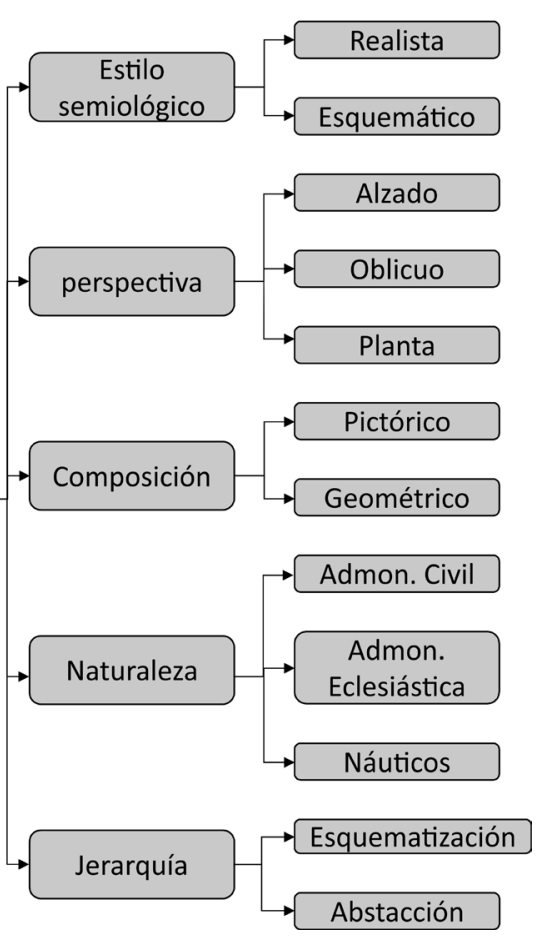

Para el establecimiento de una clasificación de signos nos hemos basado en cinco tipologías de atributos (Figura 1). Para ello, hemos adaptado a nuestro objeto de estudio el análisis llevado a cabo por Delano (2007, p. 540). Así, podemos examinar la simbología utilizada para los asentamientos según su complejidad (realista - esquemática), puntos de vista (alzado - planta) y composición (figurativo - geométrico). Pero también esta aplicación nos faculta para poder estudiar los signos según su naturaleza: civil, eclesiástico, náutico y, en menor medida, militar. La propia esencia de esta misma naturaleza nos permitirá investigarlos de modo transversal, sin necesidad de introducir un apartado propio. Por último, estaría la representación de los asentamientos según su jerarquía, explicada, en algunas ocasiones, en las propias leyendas de los mapas. Esta graduación de núcleos se ha podido establecer según dos de los tipos de recursos cartográficos más característicos: la esquematización, entendida como la simplificación del símbolo basándonos en la eliminación parcial de elementos representados; y la abstracción, es decir, los asentamientos de menor importancia son trazados mediante figuras geométricas o abstractas, especialmente el círculo.

\section{LA REPRESENTACIÓN DE LOS NÚCLEOS DE POBLACIÓN EN LA CARTOGRAFÍA REGIONAL}

Para este estudio hemos considerado que los núcleos de población no son sólo un conjunto de al menos diez edificaciones que están formando calles, plazas y otras vías urbanas como lo considera el INE (2019), sino también queremos incluir bajo este concepto a las entidades singulares, es decir cualquier área habitable. Así, y siguiendo la terminología de la cartografía de la Edad Moderna, podemos considerar dentro de nuestro objeto de estudio desde las grandes ciudades y arzobispados hasta las ventas, lugares fuertes o ermitas. De forma genérica podemos asimilar el concepto de núcleo de población al de asentamiento por ser el más adoptado en los diversos estudios sobre esta materia (Harley, 1988, p. 66; Stone, 2005, p. 290; Delano, 1985, p. 10 y 2007, p. $531 . .$.$) . Pero también, debemos tener presente que$ estos asentamientos han ido transformándose a lo largo de los siglos, ganando o perdiendo población, es decir, subiendo o bajando en el orden jerárquico y por tanto en el modo de simbolizarlos.

Debemos precisar que las ilustraciones que los describen en un mapa concreto son, ante todo, mo- 
nosémicas (Bertín, 1973, p. 6). Así pues, su significado está determinado por el autor de antemano y de forma única, esté o no representado en una leyenda cartográfica. Se hace esta última reflexión porque muchos mapas, sobre todo durante el siglo XVI y parte del XVII, carecen de leyendas aunque los signos utilizados siguen siendo monosémicos y unívocos. Hay que tener en cuenta que durante la Edad Media, no se incluía en los mapas ninguna leyenda cartográfica que explicara la relación entre el signo y su significado (Woodward, 2007a, p. 11). Esto llevó a que durante más de un siglo en los mapas de la Edad Moderna no aparecieran explicaciones de los signos empleados y su implantación, de forma genérica, fue formalizándose con lentitud.

También es de destacar una característica común a todos los núcleos representados: siempre, en la parte central del trazado de los asentamientos se dibuja un círculo, bien con un punto en el centro o sin él, que sirve de localización geográfica del elemento en cuestión. Da igual la naturaleza del signo trazado, sean éstos figurativos, realistas, esquemáticos,... en todos ellos, invariablemente, aparece un círculo que lo identifica. Esta particularidad sólo ocurre con los núcleos de población y no con otros elementos diseñados, sean estos naturales o antrópicos, desde el mapa de Jerónimo Chaves (1579) que fue una de las primeras representaciones cartográfica de una región de España (Líter, 2011, p. 122) hasta el último de los mapas analizados de finales del XVIII (López, 1797).

Estos elementos reproducidos normalmente se dibujan con una dimensión mayor de lo que deberían tener. Si los signos de estos mapas estuvieran realizados a escala deberían estar dibujados manteniendo esa relación entre el representado y la realidad. Pero en los siglos estudiados, cuando las ilustraciones de los núcleos son pictóricas, el tamaño es mucho mayor (Harley, 2009, p. 135). Si observamos la figura 2 y comparamos algunos mapas de la época, advertimos que el sobredimensionamiento es excesivo. Para comprobar exactamente las dimensiones se han calculado, como ejemplo, las zonas intramuros de Cádiz, Sevilla y Granada. Se han tomado las medidas concretas desde el punto geográfico situado más al Oeste de cada una de estas ciudades hasta el situado más al Este. No se ha tenido en cuenta las mediciones Norte-Sur porque los asentamientos están representados en alzado o en perspectiva. Si las extensiones EsteOeste actuales son de 1906 metros en Cádiz, 2172 metros en Granada y 2030 metros en Sevilla, las magnitudes en el mapa de Nicolás de Fer de 1705, por ejemplo, son más del doble, incluso en el caso de Sevilla llega a medir casi cuatro veces más. EI ejemplo dimensional de los núcleos de población de este mapa es lo normal si lo cotejamos con otros mapas de esta misma época. Pero este sobredimensionamiento llega al extremo cuando lo comparamos con el mapa de Giovanni Battista da Cassino (1712). Éste es un mapa eclesiástico donde se detallan tres tipos de asentamientos: los principales núcleos de población, los conventos y las casas de estudio de la orden de los franciscanos capuchinos. Los signos utilizados nos proporcionan unas dimensiones que, de media, las podemos multiplicar por 16, Ilegando a medir más de 33 kilómetros el núcleo de Sevilla si pasamos a la realidad la medida del dibujo empleado. Otros mapas que participan de esta característica, aunque sin llegar a ese extremo, son los de Jerónimo Chaves (1579) o el de Herman Moll (1732). En muchas ocasiones, esta exageración también se refleja en algunos de los edificios que simbolizaban a los asentamientos, principalmente en las torres de las iglesias que se dibujaban a mayor tamaño que la escala vertical teórica que le corresponde (Harley, 2009, p. 135).

Pero no sólo la dimensión es una característica determinante en los mapas de estos siglos, sino también su gran pluralidad y complejidad. Delano (2007, p. 557) desarrolla la idea de que la variedad de los signos dibujados obedece a tres tipos de atributos: composición, perspectiva y estilo semiológico. Pero, además, se produce otro tipo de modificación que se basa en la eliminación de determinados elementos en el trazo del signo que nos permiten establecer una jerarquización. Aunque debemos entender que los signos empleados para los asentamientos humanos, como elementos primarios, aparecen en la cartografía como dibujos convencionales al igual que los utilizados para el medio natural como árboles o montañas (Harley, 2002, p. 8). Es a partir de este razonamiento cuando comienza a diversificarse los símbolos cartográficos en este periodo. Con posterioridad, ya no se emplearán imágenes pictóricas o figurativas sino abstracciones simbólicas de los elementos a representar. Es en este momento cuando el efecto decorativo y su percepción visual ornamental disminuyen a favor de la claridad y precisión que identificaron a los mapas a partir de buena parte del siglo XVIII (Rees, 1980, p. 63). 
FIGURA 2

EJEMPLO DE SOBREDIMENSIONAMIENTO EN LA REPRESENTACIÓN DE LOS NÚCLEOS DE POBLACIÓN DE CÁDIZ, SEVILLA Y GRANADA*

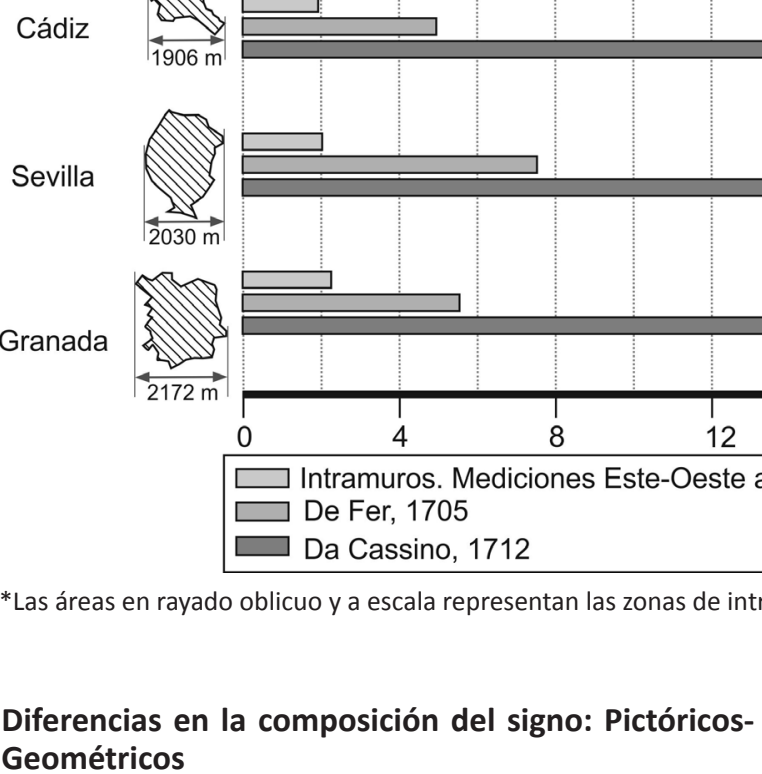

Históricamente, la composición de los signos empleados en la cartografía se ha diferenciado de dos modos posibles: los figurativos o pictóricos y los abstractos o geométricos (Bertín, 1973, p. 13). Esta dualidad también se ha mantenido e incluso se ha conjugado en un mismo mapa, principalmente cuando los signos se aplican para representar núcleos urbanos. Independientemente del periodo histórico concreto, los símbolos utilizados han oscilado entre ambas opciones. El caso del asentamiento de Carboneras (Almería), que podemos considerarlo como puerto desde el siglo XVI y fortaleza desde 1688 con la construcción del castillo de San Andrés, ejemplifica perfectamente esta diferencia en la composición de los signos (Figura 3). En el mapa de Jean-Baptiste Nolin (1720) este núcleo se muestra mediante la representación de un edificio, dibujo pictórico que refleja la esencia de un asentamiento. Tomás López y Franz Ludwig Güssefeld (1782) diferencian la fortaleza y el puerto mediante dos simbologías distintas, en ambos casos utilizando elementos geométricos. Por último, Nicolás de Fer (1705) la dibuja de la forma más simplificada posible: el círculo.

Esta figura geométrica, el círculo, ha sido la más usada a lo largo de la historia de la cartografía para representar a los núcleos de población. Incluso en la actualidad, este modo de dibujarlo es el más extendido. En muchas ocasiones va acompañado de otros elementos (Delano, 1985, p. 15; Woodward, 2007b, p. 601) que complementan el signo y di-

FIGURA 3

DIFERENCIAS EN LA COMPOSICIÓN DEL SIGNO EN CARBONERAS

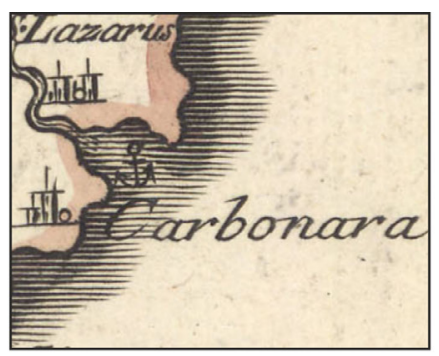

Nolin (1720)

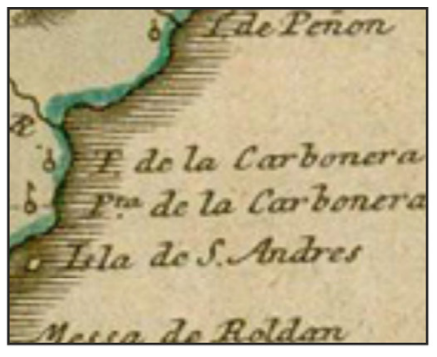

López y Güssefeld (1782)

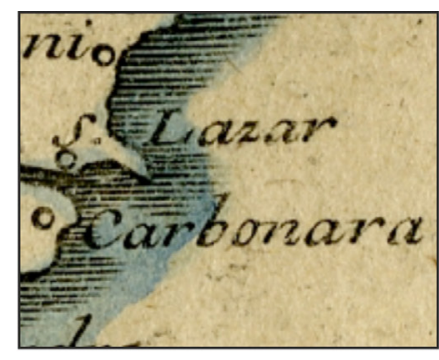

De Fer (1705)

Figurativo

Geométrico 
versifica su significado. Son los casos de los mapas de Tomás López (1767), de Pedro Alonso Eguilart (1770) o de Llobet, López, Güssefeld (1781). En estos ejemplos el círculo puede ir acompañado de una o varias líneas, rectas o curvas, que surgen de la figura originaria, normalmente de la parte superior, y que da pie a una multiplicidad de acepciones como queda reflejado en la Figura 4.

Como se puede evidenciar las variaciones de los círculos se repiten y coinciden en muchos casos por los realizados por otros cartógrafos, a pesar de ese espíritu cultural individualista que señalábamos anteriormente. Era bastante común que imitaran los signos de mapas precedentes. El ejemplo más claro es el de Pedro Alonso Eguilart de Salanoba que en 1770 copia exactamente la simbología utilizada por Tomás López en su mapa de 1767 . Incluso era normal que un mismo autor como Tomás López, que había participado también en el de Francisco Llobet de 1781, mantenga casi los mismos diseños convencionales utilizados en mapas anteriores, aunque algunos sufren leves cambios como el dibujo de las Ermitas, modificando el tipo de cruz de latina a paté, y de los Lugares Fuertes que aparecen reflejados horizontalmente en el de 1781.

Otra reflexión nos lleva a plantear el uso combinado de este elemento geométrico, el círculo, con uno figurativo. Son los denominados signos asociativos. Los dos ejemplos más evidentes los hallamos en los trazados de los monasterios (círculo y báculo) y las ermitas (círculo y cruz). Este tipo de simbología asociativa se ha mantenido hasta nuestros días, en algunos casos sin apenas modificaciones, principalmente en los mapas topográficos; sirvan como modelos los signos para dibujar los cementerios o los edificios religiosos.

A pesar de lo expuesto, no sólo es el círculo el único elemento geométrico utilizado. También se emplearon otros como el triángulo, con diferentes significados: ventas (Hoffrichter, 1673), minas (López, 1797)... Pero, debemos insistir, la representación de los asentamientos a través de símbolos pictóricos son los más extendidos, sobre todo por los más grandes cartógrafos de la época como Abraham Ortelius, Mercator, Joan Blaeu... En muchas ocasiones la apreciación de los detalles de los signos aumentaba con el uso de los colores, cumpliendo la conocida propiedad asociativa de esta variable visual (Bertin, 1973, p. 48). Aunque algunos autores utilizan variaciones de colores para establecer distintos tipos de asentamientos como en el mapa de Luis David Hoffrichter de 1673 (blanquecinos, rojizos y amarronados), lo habitual era usar exclusivamente el rojo para los núcleos de población, hecho que ha perdurado hasta la actualidad. Si el uso de este color se empleaba sobre fondos blanquecinos, amarillentos y verdosos, como en la mayoría de los mapas iluminados analizados, el contraste aumentaba considerablemente (Chaves, 1579; Salcedo de Aguirre, 1587; Hondius, 1606; Van den Keer y Janssonius, 1628; Texeira, 1634a y 1634b; Blaeu, 1634; Danckerts, 1680; Visscher, 1683; Moll, 1712; Michelot y Brémond, 1723; Espelius, 1765; etc.).

FIGURA 4

VARIACIONES DEL CÍRCULO COMO SIGNO GEOMÉTRICO MÁS REPRESENTATIVO EN LA CARTOGRAFÍA RENACENTISTA

\begin{tabular}{|c|c|c|c|c|c|}
\hline \multicolumn{2}{|r|}{ López (1767) } & \multicolumn{2}{|r|}{ Eguilart (1770) } & \multicolumn{2}{|c|}{ Llobet, López y Güssefeld (1781 } \\
\hline O & Cortijos o Caseríos & $\odot$ & Cortijos o Caseríos & O & Cortijos o Caseríos \\
\hline$\sigma$ & Ventas & & & $\sigma$ & Ventas \\
\hline 20 & Molinos & & & & \\
\hline 1 & Lugares Fuertes & $\odot$ & Lugares Fuertes & $\hat{0}$ & Lugares Fuertes \\
\hline$\oint$ & Monasterio & $\oint$ & Monasterio & 0 & Monasterio \\
\hline t & Ermitas & † & Ermitas & t & Ermitas \\
\hline
\end{tabular}




\section{Variación en la perspectiva del signo: Alzado-Planta}

El alzado es el recurso más utilizado para la representación de las poblaciones. Históricamente, desde los mapas romanos, los T-O medievales o los portulanos, la percepción horizontal de la ciudad era la forma más habitual de ilustrar los asentamientos en los mapas. Estos perfiles abatidos normalmente estaban ricamente adornados por banderolas, emblemas y edificios que los iluminadores se encargaban de embellecer. Estos mismos iluminadores añadían, en muchas ocasiones, el sombreado en los elementos trazados para conseguir un mayor realismo.

Pero no sólo los perfiles abatidos servían para identificar a las poblaciones sino también para simbolizar el relieve (Paladini, 1991, p. 12; Posada, 2011, p. 168) o la vegetación natural (Crespo, 2003, p. 48), al igual que el uso del sombreado (San Antonio y León, 2002, p. 3), que se generalizó de forma más significativa durante el siglo XVIII (Morato, 2012 , p. 28). Si tomamos como ejemplo el núcleo urbano de Sevilla (Figura 5), observamos que la variación desde la perspectiva de los signos pueden oscilar entre el enfoque horizontal hasta su trazado en planta. La forma más habitual era la representación de los núcleos urbanos en alzado como los simbolizados en los mapas de Barents y Hondius (1595), Metellus y Lambert (1595a y 1595b), Hondius (1606), Van den Keere (1632), Moll (1712) o Bonne (1762).

FIGURA 5

VARIACIONES EN LA PERSPECTIVA DEL SIGNO EN SEVILLA
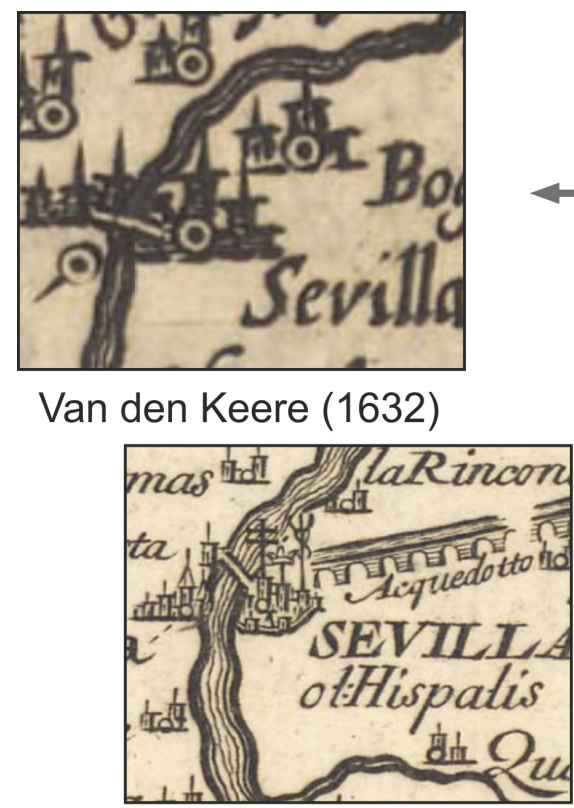

Nolin (1720)
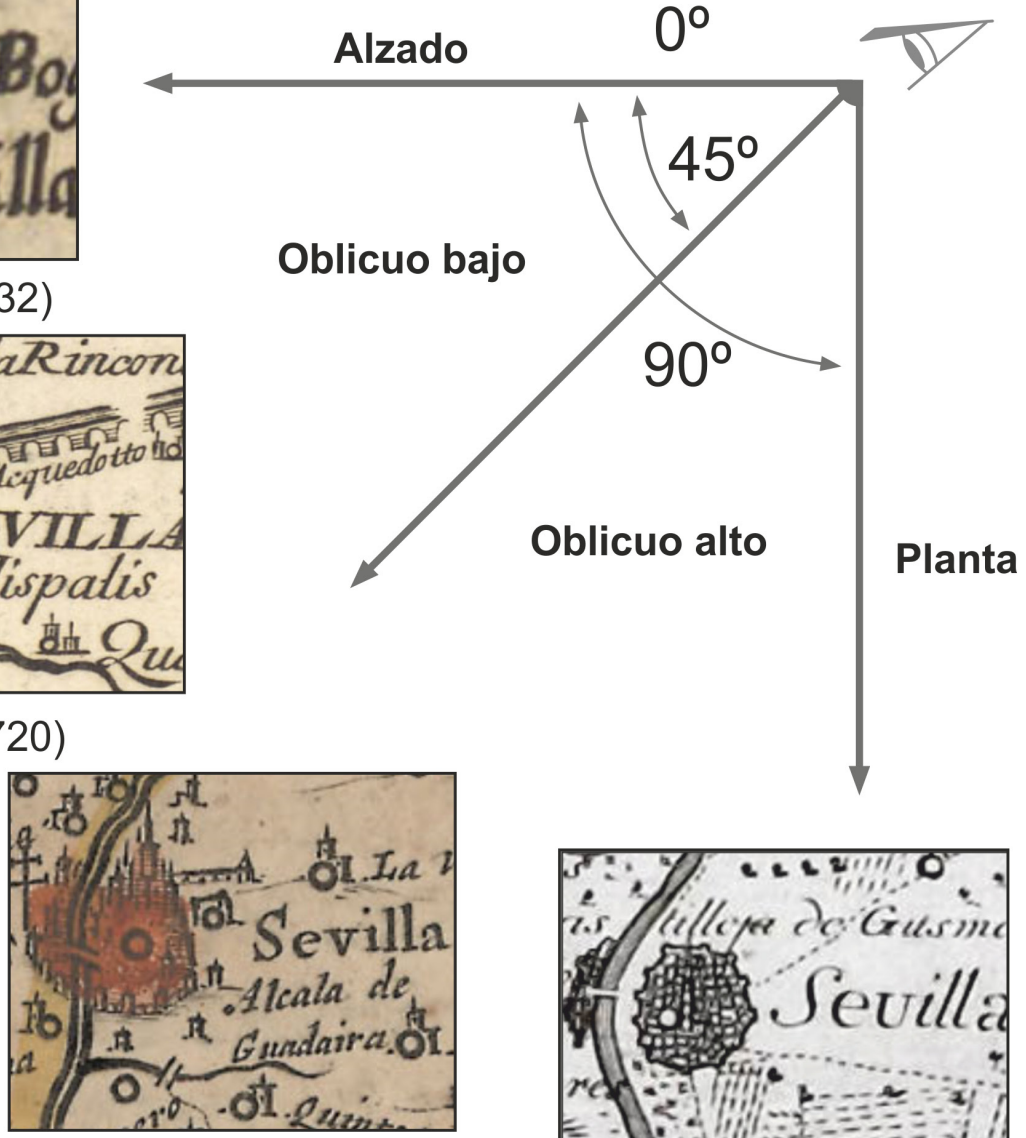

Blaeu (1646)

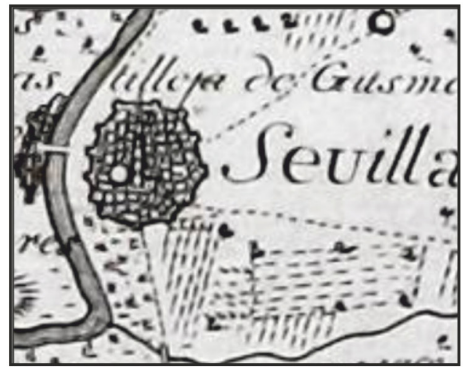

1748 - Llobet (1748) 
La necesidad de querer dar una tercera dimensión a los elementos representados hizo que los cartógrafos comenzaran a trazar los asentamientos a vista de pájaro o en perspectiva aérea (Woodward, 2007b, p. 599) y con ello conseguir una percepción más realista, sobre todo por la influencia, en cuanto al nivel de detalle de los signos, de los cartógrafos flamencos (Pujades, 2017, p. 50). Este tipo de recurso fue muy utilizado en las vistas de ciudades, donde la mayoría se presentaba a vista de pájaro (Kagan y Marías, 1998, p. 18; Posada, 2018, p. 33). Este tipo de representaciones, sean en oblicuo alto o en oblicuo bajo, conseguían plasmar unos signos muchos más expresivos y en profundidad. Con este recurso pictórico se aumenta, por tanto, las posibilidades visuales de los núcleos de población que no se conseguían con el perfil abatido, dando la sensación de más veracidad (Nuti, 1994, p. 126). Ejemplos de este tipo de mapas aparecen ya en el XVI y continúan en el tiempo hasta bien avanzado el siglo XVII (Chaves, 1579; Van Doetichum y Janszoon Waghenaer, 1583; Hondius, 1606; Blaeu, 1634; Kremer, 1663; etc.). Era común, del mismo modo, que la ratio perspectiva siguió proporcionando vistas levemente elevadas de estas ciudades (Pujades, 2017, p. 57). En algunas ocasiones se ilustraban estos núcleos dentro de sus murallas de defensa dando como resultado un realismo mayor, tal y como se puede comprobar en los mapas de Willem Janszoon Blaeu (1635), que fue uno de los principales cartógrafos en utilizar este tipo de recurso en varios de sus mapas, y de su hijo Joan Blaeu (1646). En el interior de estas murallas se dibujaba una serie de edificios a diferentes alturas que se alternaban con torres coronadas con techo cónico. Algunos autores como Buisseret (2007, p. 1088) sugieren que la importancia que le daba Willem Janszoon Blaeu, a las fortificaciones y murallas que rodeaban los asentamientos, a diferencia de otros cartógrafos, obedecía a que había trabajado anteriormente en defensas y canales.

Debemos tener presente que en casi todos estos mapas se utilizaban a la vez diferentes tipos de pers- pectivas. Fundamentalmente se empleaba la técnica a vista de pájaro para las ciudades más importantes (capitales de reinos, arzobispados, obispados...), mientras que para los demás asentamientos continuaban recurriendo al alzado. Los mapas que ilustran los núcleos de población en planta pueden ser de diversa naturaleza: civiles, militares, religiosos y náuticos. Los primeros mapas que representan los asentamientos de Andalucía desde una perspectiva vertical aparecen en 1680, antes del siglo XVII nunca se habían utilizado (Delano, 2007, p. 541). Otros cartógrafos como Frederick de Fer (1705) o Justus Danckerts (1680) publican sus respectivos mapas dibujando las ciudades más importantes con este tipo de enfoque vertical (como las capitales provinciales actuales, además de otras de cierta relevancia como Baza, Baeza, Guadix, Jerez de la Frontera, Ayamonte, Almuñécar, Lepe, Marbella, Algeciras...). Las restantes continuaban trazándose en perfil abatido, como en la mayoría de los mapas de la época. Pero también existían autores que restringían aún más el número de asentamientos representados en planta, limitándose exclusivamente a las capitales provinciales actuales salvo Huelva (Llobet, 1748). En todos estos casos se ilustraban los asentamientos humanos rodeados de una muralla. Aunque la mayoría de estas murallas son almenadas (como las de Cádiz, Sevilla, Córdoba, úbeda...) en determinados casos no se sabe exactamente si lo que representan son torreones insertos en la misma o la propia muralla almenada (Figura 6).

A finales del siglo XVII, Giacomo Cantelli (1696) cartografía únicamente a la ciudad de Cádiz de esta forma, mientras que el resto de los núcleos de población los traza, al igual que los cartógrafos precedentes, en alzado. Esta característica de seleccionar unos núcleos en planta y otros en alzado es el procedimiento más común y extendido en esta época. En el caso andaluz, la cantidad de asentamientos seleccionados dibujados de un modo u otro es la mayor discrepancia que existe entre los diferentes

FIGURA 6

DISTINTOS MODOS DE REPRESENTAR A CÁDIZ EN PLANTA

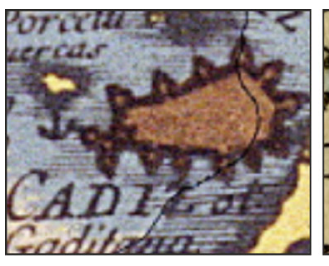

Cantelli y De Rossi (1696)

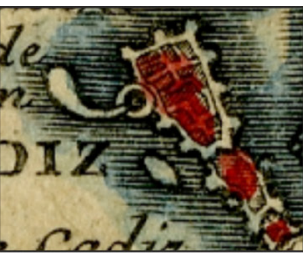

De Fer (1705)

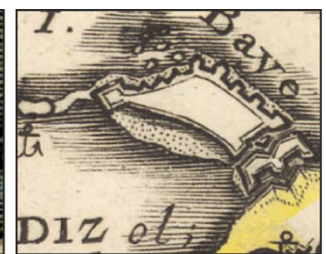

Nolin (1720)

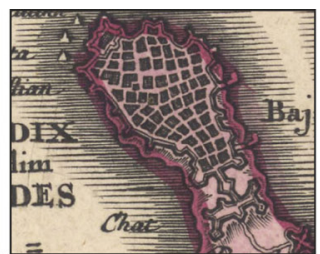

Seutter (1730)

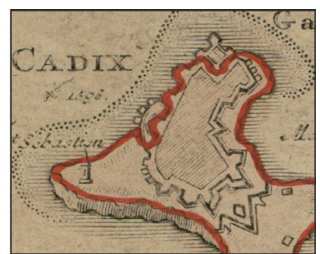

Heirs (1730) 
mapas. Así, Matthäus Seutter (1730), Antonio Zatta (1776) o Giovanni Maria Cassini (1794) coincidían en simbolizar a casi todos los núcleos en planta. Otros, en cambio, se limitaron a cartografiar de este modo exclusivamente los asentamientos costeros, recurso que se popularizó entre las cartas náuticas (Homann Heirs, 1730) y, en menor medida, entre mapas de otra naturaleza (Espelius, 1765). Excepciones a este argumento las observamos en la carta náutica de Joseph Roux (1764) que sólo representa en perspectiva vertical a Cádiz y Gibraltar. En este mismo mapa Roux recurre al cuadrado, otra figura geométrica empleada en la cartografía de la época, para representar a los castillos o torres fortín (Posada, 2010, p. 23). En ocasiones se resalta las esquinas de estos cuadrados para simbolizar los de mayor importancia: Castillo de San Andrés en Carboneras, Torre de Macenas en Mojácar, Castillo de Malerva en Balerma, la Fortaleza de Vélez Málaga, el Castillo Sohail en Fuengirola... Pero principalmente es el núcleo de Cádiz el que se dibujaba en planta, a veces acompañado por Ceuta, que se solía trazar de este modo por su situación geoestratégica (Nolin, 1720), o junto con Gibraltar (De Fer, 1707) por la misma razón.

Del mismo modo, hubo un apogeo creativo entre los cartógrafos holandeses que consistía en trazar alrededor del mapa varios planos de las ciudades más importantes. Así, el cartógrafo Van den Keere (1632) proyecta 12 planos de estas poblaciones alrededor de la región andaluza. Si observamos con más detenimiento dichos planos comprobamos que no se asemejan a la realidad, representando las manzanas intramuros no sólo de forma inexacta sino totalmente inventada. De hecho, esta moda dejó de utilizarse por lo absurdo de plantear estos planos a una escala menor y no ofrecer detalles verosímiles de estas ciudades (Fordham, 1927, p. 35).

\section{Transición del estilo semiológico del signo: Realista-} Esquemático

No podemos sistematizar y determinar qué cartógrafos utilizan un estilo semiológico u otro. La realidad es que un mismo autor puede emplear varios, bien en el mismo mapa o en otros distintos. Como ejemplo, Mercator, en sus numerosos mapas utiliza a la vez signos pictóricos y abstractos, esquemáticos y naturalistas, en perfil abatido y en perspectiva aérea... (Delano, 2007, p. 540). Por tanto, cuando hablamos de estilo semiológico debemos referirnos exclusivamente a mapas y no a cartógrafos, ya que éstos pueden variar los signos adoptados de un mapa a otro.

La transición del estilo semiológico se refiere a los signos pictóricos o figurativos de estos elementos representados que puede variar obedeciendo a diferentes características. En primer lugar, están aquellos mapas que muestran los núcleos de un modo realista hasta los que no han dudado en representarlos esquemáticamente. Si tomamos como ejemplo la ciudad de Sevilla (Figura 7) observamos que hay mapas que intentan plasmar los núcleos de población por medio de una serie de edificios a diferentes alturas, normalmente en perspectiva oblicua. En el interior de cada signo aparecen una serie de elementos estándar similares a otros asentamientos simbolizados en el mapa, por lo que la singularidad de las poblaciones está prácticamente ausente en el mapa (Harley, 1988, p. 68). Pero en otras ocasiones dicha ilustración va acompañada con algún elemento característico que lo identifica claramente. Como ejemplos estarían por un lado el de la ciudad de Sevilla, con la presencia de Triana y el puente de las Barcas sobre el Guadalquivir como elementos singulares aplicados, y por otro el de Carmona a través de su acueducto. Entre los diferentes cartógrafos que presentan ambas particularidades estarían: Chaves (1579), Texeira (1634a y 1634b); Blaeu (1634), Cantelli y De Rossi (1696), Nolin (1720), Vagoundy (1751), Zatta (1776), etc.

FIGURA 7

VARIACIÓN DEL ESTILO SEMIOLÓGICO DE SEVILLA

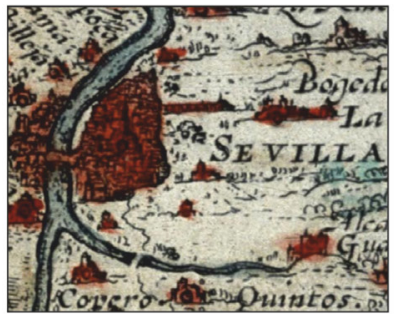

Chaves (1579)

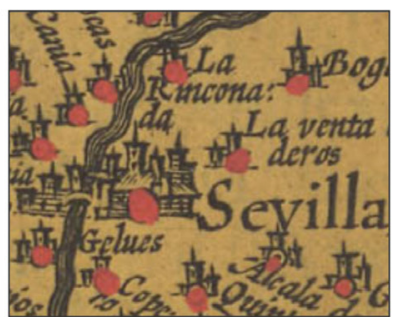

Hondius (1606)

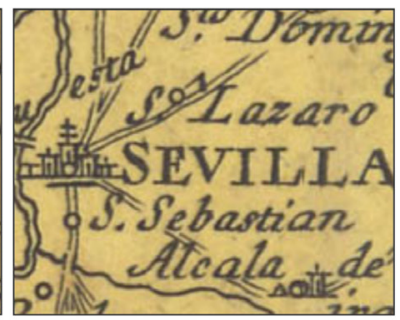

Llobet, López y Güssefeld(1781)

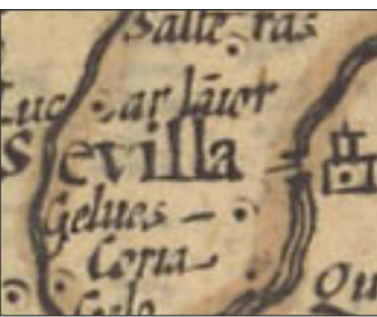

Hondius (1635)

Realista

Esquemático 
Conforme este grado de realismo va disminuyendo, se va produciendo una generalización o reducción de las líneas que componen el signo, consiguiéndose un trazado sintético, pero sin llegar nunca a ser geométrico o abstracto. Evidentemente esta simplificación está en estrecha relación con el uso de las planchas de cobre o madera, por la mayor dificultad que tenían en el momento de reproducir los signos, reemplazando gradualmente a las imágenes pictóricas más realistas (Rees, 1980, p. 63) y mucho más complejas de grabar por otras más sencillas. Aunque estos dos tipos de planchas coexistieron, fue el grabado en cobre el más habitual para la cartografía impresa (Pelletier, 2009, p. 39). Según Olmedo (2011, p. 21) de todos los mapas referentes a Andalucía realizados entre los siglos XV y XVIII, los grabados en madera apenas llegan al 2,5\%.

Aunque en cierta medida los signos esquemáticos preceden a los abstractos o geométricos, no podemos olvidar que desde el principio, las representaciones de los asentamientos siempre han tenido el círculo como figura geométrica principal en su trazado. Éstos se complementaban, en mayor o menor medida, con edificios diseñados a su alrededor, según el estilo semiológico del cartógrafo. Por tanto, la forma más simple de emplear este tipo de signo esquemático sería a través de un único edificio que era el elemento más sencillo e interpretativo de un núcleo de población. Este edificio se mostraba mediante una torre que a veces estaba coronada por un techo cónico (Hoffrichter, 1673; Visscher, 1683) o, en mayor medida, por uno plano (Hondius, 1606; Van den Keere, 1632; Du Val, 1688; López, 1767; López y Güssefeld, 1782), pero siempre detrás o junto a un círculo. En muy raras ocasiones la representación de los asentamientos carece de este círculo como en el mapa de Willem Barents y Jodocus Hondius (1595).

\section{JERARQUIZACIÓN DE LOS SIGNOS EN LOS NÚCLEOS DE POBLACIÓN}

La jerarquización de los símbolos ha sido y es una herramienta muy habitual entre los cartógrafos. En la actualidad la ordenación de los asentamientos, con implantación puntual, se limita a la dimensión del dibujo empleado. Su aplicación se basa casi exclusivamente en aumentar o disminuir el tamaño de dicho signo en base a dos variables: organización administrativa y población. Entre los siglos XVI y XVIII los diseños de los asentamientos, independientemente de su tipología (pictórica o abstracta) se muestran de manera proporcional al rango de los lugares representados. Pero si en la actualidad esta jerarquización se basa en variables como las enunciadas anteriormente, en la Edad Moderna se fundamentaba en ordenaciones legales, feudales (que todavía perduraban) y eclesiásticas (Harley, 2009, p. 138). En algunas ocasiones a estos mapas les acompañan una leyenda en la que se incluían hasta cinco o seis símbolos (Delano, 2007, p. 532), aunque en algunas ocasiones cartógrafos como Tomás López (1767) rebasaban ampliamente este número (15 elementos gráficos, 5 caracteres alfabéticos y 26 códigos numéricos). Pero lo normal era que la cantidad de signos distintos fueran muchos menos y por ende el número de diferentes tipos de asentamientos. Estas leyendas, además, tenían diferentes cabeceras: Notarum Explicatio, Notas Universales, Explicación de las Señales o Explicación de las Notas.

Otra forma de jerarquizar los núcleos de población se basaba no tanto en el signo como en su topónimo. Para ello, se utilizaban dos recursos distintos, en primer lugar, y muy extendido entre los portulanos, era valerse del rojo y el negro para categorizar los asentamientos costeros (Woodward, 2007b, p. 595). Utilizaban el rojo para las ciudades costeras más significativas y en negro para los asentamientos menores. También podrían sustituirse los colores por el uso de topónimos escritos en vertical y en cursiva (más y menos importantes respectivamente). Otra manera de jerarquizarlo era empleando las mayúsculas para los núcleos principales. Estos podían escribirse, aunque no siempre, en negrita. Para los núcleos de un segundo nivel que se utilizaban las minúsculas. Por último, un tercer escalón estaba compuesto por los asentamientos menos significativos que se trazaban en cursiva (Bonne, 1762; Roux, 1764; Llobet, López y Güssefeld, 1781).

\section{El uso de las variables visuales en el proceso de jerarquización}

Desde una perspectiva semiológica, las tres variables visuales que más se utilizaban para el establecimiento de las jerarquías urbanas eran el tamaño, la forma $y$, en menor medida, el tono. El tamaño, cuando se aplicaba a fenómenos puntuales, como es el caso que nos ocupa, se refería a la dimensión del símbolo en sí. Esta variable visual cumple la propiedad ordenada, además de la selectiva y la cuantitativa, por lo que desempeña la función de clasificación entre los diversos núcleos de población. Pero el tamaño no es la única variable que se aplica para representar los asentamientos, sino que va acompañado de otras, como se puede comprobar en la mayoría de los mapas analizados. La variable visual forma enfatiza los 
contrastes en la ordenación de los distintos asentamientos, principalmente por emplearse junto al tamaño. Aunque la forma no cumple la propiedad ordenada, sólo la asociativa, al utilizarse de este modo, sí nos permite una distinción evidente y perceptible entre las distintas categorías de asentamientos. Como ejemplo de este uso complementario entre tamaño y forma destacamos los mapas de Willem Barents y Jodocus Hondius (1595), Jean-Baptiste Nolin (1720) o Robert de Vagoundy (1751).

El color es la tercera variable visual que se emplea en estos mapas. Aunque en la actualidad es la variable más importante, en este periodo quedaba supeditado al tamaño y a la forma. De los tres componentes del color: tono, valor y saturación; sólo se empleaba mayoritariamente el tono. El uso de un solo color, el rojo, es el que se aplicaba para los diferentes tipos de asentamientos. Éste se empleaba con coberturas de pintura más o menos transparentes que permitían ver el trazado de los signos. Si tomamos como modelo el mapa Hispalensis Conventus Delineatio de Jerónimo Chaves (1579) observamos que los distintos iluminadores que habían coloreado las diversas versiones lo habían realizado de desiguales modos. Unos cubriendo los núcleos de población con una cobertura de rojo que apenas deja ver las líneas de los signos como el ejemplar de la Biblioteca Nacional de España y otros, en cambio, utilizando un tono de carmín más aguado que permite percibir de manera más clara el dibujo de los asentamientos, como en la edición que se encuentra en la Universidad Politécnica de Valencia.

Pero si aplicamos el uso del tono a la jerarquización de los núcleos podemos distinguir entre aquellos mapas que aplican este color para todos los núcleos (Chaves, 1579; Texeira, 1634a y 1634b; Da Cassino y DureIli, 1712 , etc.) y los que lo usan exclusivamente para los asentamientos más importantes (Hondius, 1606; Kremer, 1663; Danckerts, 1680; Visscher, 1683; De Fer, 1705; etc.). Esta variedad propia de la idiosincrasia renacentista provoca que incluso dentro de cualquiera de esos grupos encontremos también características distintas. Por ejemplo, la versión del mapa de Jodocus Hondius (1606) que se encuentra en la cartoteca del Instituto Geográfico Nacional solo está iluminado en rojo el círculo central de cada signo mientras que los edificios que lo rodean están sin colorear. El caso contrario sería el de Pedro Texeira (1634a) que emplea un color diferente para el círculo central mientas que los edificios están coloreados en rojo. En muchas ocasiones estos mapas o algunas de sus ediciones no estaban iluminados ya que esta técnica se realizaba una vez impreso el mapa. Sirvan de ejemplos de mapas sin iluminar los de Van den Keere (1632), Du Val (1688), Cantelli y De Rossi (1696), De Fer (1707), Van der Aa (1714), Seutter (1730), López (1761), Bonne (1762); Roux (1764), Llobet, López y Güssefeld (1781), Cassini (1794), etc. Incluso se dejaba la opción de que el comprador de estos mapas eligiera si lo quería iluminado o no, lo cual encarecía, evidentemente, el valor del mapa (Jiménez, 2016, p. 143).

\section{Jerarquización de los núcleos de población mediante la esquematización y la abstracción}

Junto a estas tres variables visuales existen dos procesos de jerarquización empleados en este periodo histórico. Tal y como hemos reseñado anteriormente, el proceso de esquematización y el de abstracción son las formas más extendidas para jerarquizar los asentamientos. El primero de ellos es el de esquematización, entendido como la simplificación del signo por la eliminación parcial de elementos arquitectónicos representados (Figura 8). Ejemplos de este tipo de esquematización lo vemos, aparte de los que aparecen en la figura 8, en los mapas de Jerónimo Chaves (1579), Pedro Texeira (1634a y 1634b), Jean-Baptiste Nolin (1720), Tomás López (1761) o el de Rigobert Bonne (1762).

Queda patente que si comparamos los núcleos de población de mayor importancia (denominadas urbes célebres, ciudades, arzobispados, ciudad episcopal, ciudad capital,...) observamos que se trazan empleando una serie de características comunes a todos ellos. En primer lugar la existencia de un círculo central que permite ubicar el núcleo en unas coordenadas concretas. Esta característica se extiende también a todas las poblaciones representadas, independientemente de su posición jerárquica. En segundo lugar, si los asentamientos están dibujados en perfil abatido la presencia de edificios se distribuye de forma pareja a ambos lados del círculo (Hondius, 1606; Hoffrichter, 1673; López, 1767; López y Güssefeld, 1782; Espinalt y García y Cucó, 1795); en el caso de que estén trazados en perspectiva aérea se proyectan a su alrededor (Chaves, 1579; Texeira, 1634a y 1634b; Nolin, 1720). Otra particularidad es que puede trazarse una muraIla defensiva en este tipo de núcleos (Visscher, 1683, Seutter, 1730). En otras ocasiones los asentamientos principales pueden mostrarse en planta mientras que los restantes se proyectan en alzado, utilizando para ello la técnica de la perspectiva como principal recursos para establecer la jerarquía de las poblaciones (Heirs, 1730). 


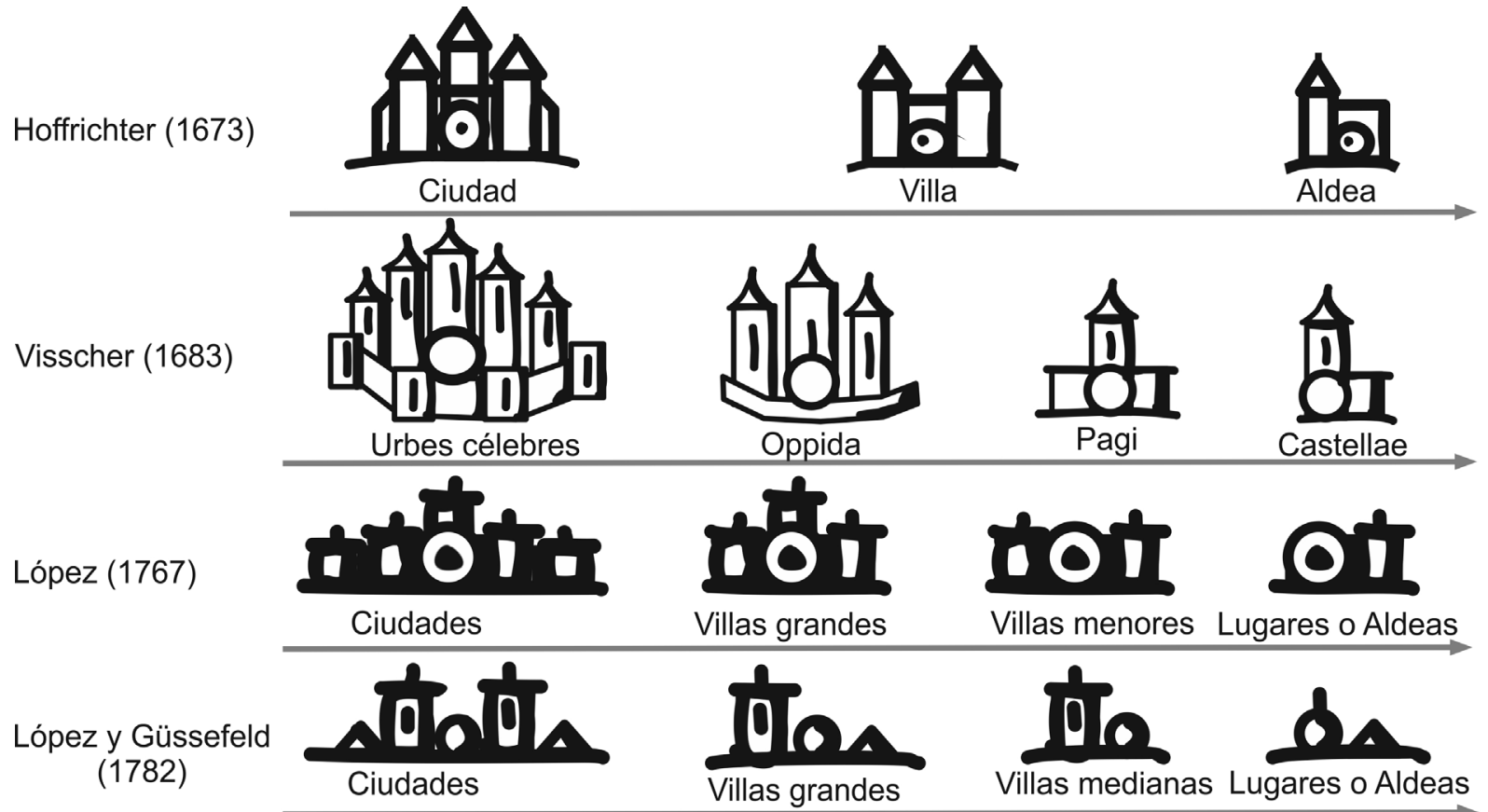

Eliminación de elementos arquitectónicos

* La reproducción de los signos se ha realizado según sus respectivas leyendas cartográficas

Por otro lado, cuando hablamos de abstracción los asentamientos de menor importancia sustituyen su grafismo iconográfico o pictórico por uno abstracto, normalmente un círculo. Este recurso semiológico comenzó a extenderse a partir del segundo tercio del siglo XVII en los mapas regionales de Andalucía. La diversidad de tipología de núcleos permitió que algunos cartógrafos emplearan variaciones del círculo como principal técnica cartográfica para diferenciar los distintos tipos de asentamientos como vimos en la figura 4. El empleo del círculo varía de unos cartógrafos a otros, desde los que sólo lo utilizan para representar los asentamientos de menor importancia, dibujando apenas una docena de este modo (Van den Keere, 1632), hasta aquellos que lo aplican a la mayoría de los núcleos salvo las principales poblaciones (Hondius, 1635) o incluso para cartografiar a todos los asentamientos través de este signo geométrico (Flórez y De La Peña, 1752) o exceptuando exclusivamente al núcleo de Sevilla (Briet, 1649). Entre ambos extremos existe una gran variedad de posibilidades cuantitativas (Sanson d'Abbeville y Sommer, 1652; De Fer, 1705 y 1707; Da Cassino y Durelli, 1712; Van der Aa, 1714; Seutter, 1730; Vagoundy, 1751; Zatta, 1776;
Llobet, López y Güssefeld, 1781). A todas estas posibilidades debemos unirles aquellas que representan los núcleos más importantes en planta, los intermedios en perfil abatido y los menores utilizando los círculos (Danckerts, 1680; Cassini, 1794).

\section{Organización de los asentamientos eclesiásticos}

Al principio de la Edad Moderna los signos cartográficos de los asentamientos eclesiásticos se dibujaban en casi todos los mapas. Cartógrafos como Mercator, en su mapa de Europa de 1554, explica el significado de las representaciones de los asentamientos religiosos, pero no sobre los núcleos laicos trazados en el mapa (Delano, 2007, p. 565). Del mismo modo, en los primeros mapas regionales de Andalucía que tienen leyendas, éstas se limitan a establecer una tipología de núcleos eclesiásticos (arzobispados y obispados) a los que se les unía las ciudades universitarias, denominadas academias, dando testimonio de la organización social de la religión católica de este periodo (Figura 9). Esta manera de enfatizar los asentamientos eclesiásticos y no los civiles, hacía que aumentase la percepción del poder de la iglesia en la sociedad (Harley, 2009, p. 138). Con posterioridad, las leyendas 
de los mapas se fueron ampliando, incluyendo otros elementos (ciudades, villas, aldeas, lugares, cortijos, ventas...). Por consiguiente, se añadió a la jerarquía administrativa de la iglesia la del estado.

En la jerarquía eclesiástica estaban en primer lugar los arzobispados, constituidos por Sevilla y Granada. Normalmente el signo utilizado era la doble cruz que sobresalía por encima de la representación pictórica del núcleo urbano. Los ejemplos de este tipo de simbolización son muy numerosos: Texeira (1634a y $1634 b)$, Blaeu (1634 y 1635), Sanson d'Abbeville y Sommer (1652), Kremer (1663), Du Val (1688), Cantelli y De Rossi (1696), Da Cassino y Durelli (1712), Nolin (1720), Vagoundy (1751), Bonne, 1762; Llobet, López y Güssefeld, 1781, López y Güssefeld (1782), Cassini (1794), Espinalt y García y Cucó (1795). Si era representado en planta la doble cruz se situaba junto al núcleo, en un espacio que no interfiriera con otros elementos dibujados (Visscher, 1683).

A un segundo nivel se encuentran los obispados que se representaban por una cruz simple. En el caso de Andalucía estaríamos haciendo referencia a Almería, Baeza, Cádiz, Córdoba, Guadix, Jaén y Málaga. La muestra de mapas del párrafo anterior también nos podría servir de modelos para el caso de los obispados. En algunas ocasiones la cruz simple latina se sustituía por una cruz paté (Kremer, 1663). En otros mapas que hacen referencia a periodos históricos precedentes aparecen más obispados que los mencionados. Es el caso del mapa de Enrique Flórez (1752) en el que señalan a Tucci (Martos), Eliberi (Elvira), Abdera (Adra), Asido (Medina Sidonia), Aegrabo (Cabra), Itálica y Elepla (Niebla) como antiguos obispados en la división administrativa de la iglesia católica en el periodo visigodo, aunque no incluye, quizás por error, a Astigi (Écija). Cartógrafos como Nicolás de Fer (1705 y 1707) plantea en sus mapas dos posibilidades distintas. En el primero de 1705 distingue los núcleos eclesiásticos a través de una cruz simple, sin especificar si son arzobispados u obispados; y en el siguiente, en 1707, ya establece esa distinción.

En la tercera categoría estarían las academias. El hecho de incluir a las academias dentro de esta clasificación obedece posiblemente a que todavía se mantenía el concepto medievalista de establecer esa estrecha relación que existía entre estas academias y las escuelas catedralicias y monásticas (impartidas, tal y como indica su nombre, en las catedrales y mo-

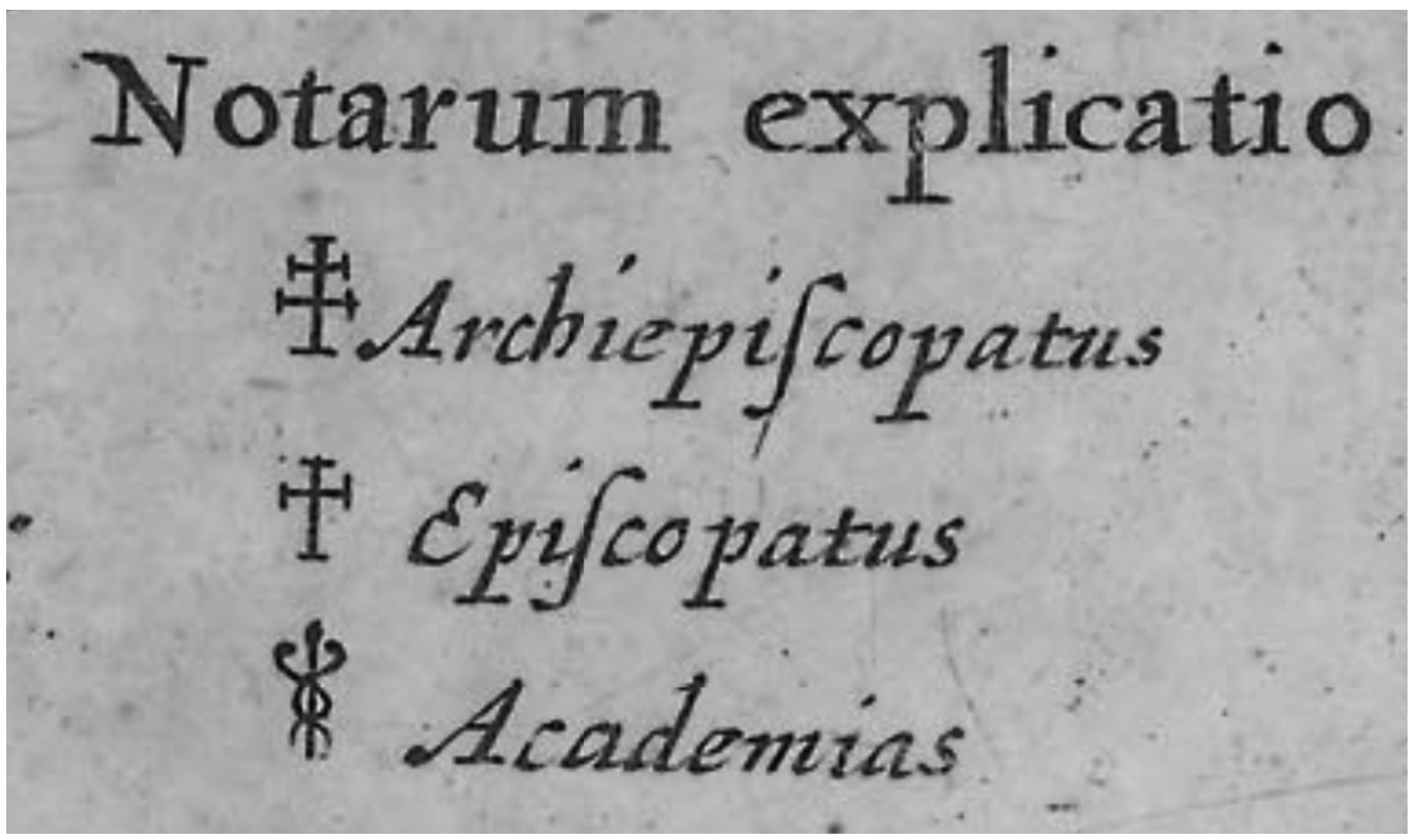


nasterios). Dos tipos de signos son utilizados para representar a las academias, en primer lugar, y más extendido, es el signo de dos serpientes que se entrelazan alrededor de una vara. No podemos decir que sea un caduceo porque en ningún caso aparecen las típicas alas al final de la vara (Blaeu, 1646; Kremer, 1663; Visscher, 1683; Cantelli y De Rossi, 1696; Van der Aa, 1714; Nolin, 1720). El otro signo convencional, tiene forma de un asterisco ubicado al final de una vara simple. En este caso su difusión entre los cartógrafos de la época fue mucho menor (Da Cassino y Durelli, 1712). Posteriormente Tomás López en su Atlas Geográfico de España de 1804 emplea este signo para designar a las nuevas poblaciones y a las villas con asientos en cortes.

Por último, y no en todos los mapas, aparecen otros símbolos que hacen referencia a entidades eclesiásticas menores como monasterios, conventos o ermitas. Por regla general los signos empleados para estos asentamientos son asociativos. Como dijimos anteriormente, el uso de los círculos es la principal herramienta cartográfica que se utiliza para representar estos tipos de asentamientos.

\section{CONCLUSIONES}

A lo largo de este artículo hemos pretendido analizar los signos cartográficos de los núcleos de población empleados en los mapas de la Edad Moderna a una escala regional tomando como referencia a Andalucía como territorio objeto de estudio. La comparación entre todos los mapas examinados nos ha permitido diferenciar la existencia de unos modelos de signos que han sido empleados de forma asidua entre los diferentes cartógrafos y a lo largo del tiempo, pero, simultáneamente, hemos comprobado que en algunas ocasiones se ha utilizado un tipo de simbología convencional cuya reproducción se ha limitado exclusivamente a un único mapa.

Los signos cartográficos usados se han representados con una dimensión mayor a la escala utilizada. Este hecho nos permite evidenciar que determinados núcleos de población como las principales ciudades o arzobispados, se han cartografiado exagerándolos con un tamaño mucho mayor que los núcleos intermedios, y estos a su vez que los asentamientos menores. Este sobredimensionamiento dependía también de la naturaleza de los mapas. Por ejemplo, para los mapas eclesiásticos, los arzobispados tenían una extensión excesiva en perjuicio de las ermitas. En las cartas náuticas los asentamientos que tenían un mayor tamaño eran los costeros en detrimento de los del interior. En los mapas civiles eran las capitales de los cuatro reinos que conformaban Andalucía los que se beneficiaban de esta técnica mientras que ciudades menores quedaban visiblemente mermadas.

Desde los primeros mapas analizados, el alzado o perfil abatido ha sido el recurso más utilizado para la representación de las poblaciones. Pero con el paso del tiempo y para aumentar el realismo en los elementos simbolizados, se vieron en la necesidad de querer dar una tercera dimensión a los asentamientos, por lo que los cartógrafos comenzaron a dibujar los núcleos de población en perspectiva aérea incluyendo el sombreado como principales recursos. A pesar de este cambio, en la mayoría de los mapas sólo utilizaban este modo de simbolización en las ciudades más importantes, mientras que el resto continuó trazándose en alzado. Incluso cuando los signos de estos elementos vuelven a cambiar y comienzan a proyectarse en planta, sólo se aplica a los núcleos principales, continuando los demás en perfil abatido.

El hecho de representar a los núcleos de una forma más exacta obligó a los cartógrafos a utilizar elementos extraídos de la realidad y proyectarlos en el mapa. El ejemplo más utilizado y extendido entre los cartógrafos es el de los puentes entre las diferentes partes que conforman una la ciudad (Sevilla, Córdoba, Écija o Jerez de la Frontera), además de emplear otros elementos característicos que los identificasen como, por ejemplo, ubicar a los asentamientos serranos sobre una montaña sombreada y en perfil abatido o dibujar un monumento propio del lugar.

Finalmente, tres son las variables visuales que más se han utilizado en el establecimiento de las jerarquías urbanas. Principalmente se ha usado el tamaño y la forma, de modo conjunto, para simbolizar los asentamientos. En aquellos casos que se ha empleado el alzado se ha utilizado el mismo signo para cada tipo de núcleo del orden jerárquico establecido (ciudad, villa grande, villa mediana, aldea, cortijo...). El empleo del color, en este caso el tono rojo, ha servido principalmente para contrastar y resaltar más las poblaciones respecto al fondo del mapa pero no para establecer una categorización de signos. En último lugar de esta jerarquía estaría los asentamientos de menor importancia que solían estar dibujados por un único edificio o por medio de un círculo. 


\section{Bibliografía}

Bertin, J. (1973). Sémiologie graphique: Les diagrammes-Les réseaux-Les cartes. Gauthier-VillarsMouton \& Cie. $431 \mathrm{pp}$.

Buisseret, D. (2007). "Spanish Peninsular Cartography, 1500-1700", en Woodward, D (ed.), The History of Cartography, Vol. 3: Cartography in the European Renaissance, pp. 1069 - 1094 Chicago: University of Chicago Press.

Cortese, V. G. \& Membribe, A. (2008). "Contribuciones teórico-metodológicas para el análisis de la producción cartográfica", Boletín Geográfico, (31), pp. 353-365.

Crespo Sanz, A. (2003). "La representación de los bosques en la cartografía antigua: el Atlas de El Escorial", Cuadernos de la Sociedad Española de Ciencias Forestales, (16), pp. 47-54. Recuperado de http://secforestales.org/publicaciones/index. php/cuadernos_secf/article/view/9348

Delano-Smith, C. (1985). "Cartographic Signs on European Maps and Their Explanation before 1700". Imago Mundi, 37, pp. 9-29. https://doi. org/10.1080/03085698508592585

Delano-Smith, C. (2007). "Signs on Printed Topographical Maps, ca. 1470-ca. 1640" en Woodward, D. (Ed), The History of Cartography, Volume 3: Cartography in the European Renaissance, pp. 528 - 590. University of Chicago Press,

Fordham, H.G. (1927). Maps: Their History, Characteristics and Uses: A Handbook for Teachers (2. ed.). Cambridge: Cambridge University Press, 83 pp.

Harley, J. B. (1988). "Silences and secrecy: the hidden agenda of cartography in early modern Europe", Imago mundi, 40(1), pp. 57-76. https://doi. org/10.1080/03085698808592639

Harley, J. B. (2002). The new nature of maps: essays in the history of cartography. JHU Press. 352 pp.

Harley, J. B. (2009). "Maps, knowledge, and power", Henderson, G. L., y Waterstone, M. (Eds.), Geographic thought: a praxis perspective, Routledge, pp. $129-148$.

INE (2019). Nomenclátor. Relación de unidades poblacionales (Metodología). Madrid. Recuperado de http://www.ine.es/nomen2/Metodologia.do.

Jiménez Garcés, J. A. (2016). La obra de cartógrafo Cano y Olmedilla y su mapa de la América Meridional de 1775, (Tesis Doctoral, Universidad Complutense de Madrid). 426 pp.
Kagan, R., y Marías, F. (1998). Imágenes urbanas del mundo hispánico (1493-1780). Madrid, Ed. El Viso. $348 \mathrm{pp}$.

Líter Mayayo, C. (2011). “Andalucía en la cartografía española. Siglos XVI a XIX", en Olmedo Granados, F. y Cortés José, J. (Eds.), Andalucía, la imagen cartográfica hasta fines del siglo XIX. Instituto de Cartografía de Andalucía, pp. 119-144.

Mendoza Vargas, H. y Lois, C. (2009). "Viejos temas, nuevas preguntas: la agenda de la historia de la cartografía iberoamericana hoy", en Mendoza Vargas, H. Y Lois, C. (Eds.), Historias de la cartografía de Iberoamérica: Nuevos caminos, viejos problemas, México. Instituto de Geografía, UNAM, pp. 9-17

Monmonier, M. (1991). How to Lie with Maps, The University of Chicago Press. 222 pp.

Morato-Moreno, M. (2012). “Representación del territorio en la cartografía regional renacentista. Algunos ejemplos", Boletín de la Asociación de Geógrafos Españoles, 59, pp. 25-48. http://dx.doi. org/10.21138/bage.1448

Nuti, L. (1994). "The Perspective Plan in the Sixteenth Century: The Invention of a Representational Language", Art Bulletin 76, pp.105-128. https://doi. org/10.2307/3046005

Olmedo Granados, F. (2011). "Evolución de las técnicas de reproducción de mapas", PH: Boletín del Instituto Andaluz del Patrimonio Histórico, 19(77), pp. 20-23.

Paladini Cuadrado, Á. (1991). "La representación del relieve en los mapas a lo largo de la Historia". Servicio Geográfico del Ejército. Boletín de Información, $\mathrm{n}$ ㅇ 72, pp.11- 49.

Pelletier, M., (2009). De Ptolémée à La Guillotière (XVe -XVIe siècle). Des cartes pour la France pourquoi, comment?, París, Comité des travaux historiques et scientifiques. $192 \mathrm{pp}$.

Posada Simeón, J.C. (2010). “Islarios. El Tránsito de la Cartografía Medieval a la Renacentista a Través de la Semiología Cartográfica de los Islarios de da Li Sonetti, Bordone y Porcacchi", en Posada Simeón, J. C. y Peñalver Gómez, E. (Eds), Cartografía Histórica en la Biblioteca de la Universidad de Sevilla. Santander. Secretariado de Publicaciones de la Universidad de Sevilla, pp. 32-63. 
Posada Simeón, J.C. (2011). “Diseño y simbolismo en el Al-Andalus de Al-Idrisi". En Tahiri, A. (Ed.), Itinerários e Reinos. Uma descoberta do mundo. $O$ Gharb al-Andaluz na obra do geógrafo al Idrisi, Aitoutouhen Temsamani (Edição Bilingue: árabe português) Fundação al-Idrisi Hispano Marroquina para a Investigação Histórica, Arqueológica e Arquitectónica \& Câmara Municipal de Vila Real de Santo António, pp. 139 - 152.

Posada Simeón, J.C. (2018). De la cartografía española a las vistas de la ciudad de Sevilla en el siglo XVII, en Palomero Paramo, J. (Ed.), Murillo y SeviIla (1618-2018). Sevilla. Editorial Universidad de Sevilla, pp. 23-39

Pujades i Bataller, R J. (2017). “Vistas urbanas ibéricas: la percepción de unos modelos importados (siglos XIV-XVI)", en L. Urteaga y F. Nadal (eds.). Historia de la cartografía urbana en España: modelos y realizaciones, pp. 49-81. Madrid, Instituto Geográfico Nacional.

Rees, R. (1980). "Historical links between cartography and art", Geographical review, Vol. 70, No. 1, pp. 61-78. Doi: 10.2307/214368

San Antonio Gómez, C. D. (2006). “Metodología para el análisis gráfico de la cartografía histórica", en Actas del XVIII Congreso Internacional de Ingeniería Gráfica (INGEGRAF). Recuperado de https:// www.researchgate.net/publication/228829064_ Metodologia_para_el_analisis_grafico_de_la_ cartografia_historica.

San Antonio Gómez, C. D., y León Casas, M. A. (2002). "La cartografía aplicada a la representación de las obras públicas españolas en el siglo XVIII" En Actas y CD del XVI Congreso Internacional de Ingeniería Gráfica. Zaragoza. Recuperado de http:// www.egrafica.unizar.es/ingegraf/pdf/comunicacion17076.pdf

Stone, J. C. (2005). "The cartographic signs and content of Blaeu's maps of Scotland", Scottish Geographical Journal, 121(3), pp. 289-296. https:// doi.org/10.1080/00369220518737239

Woodward, D. (2007a). "Cartography and the Renaissance: continuity and change", en Woodward, D. (ed.), The History of Cartography, vol. 3, Cartography in the European Renaissance, pp. 3-24. University of Chicago Press.

Woodward, D. (2007b). "Techniques of Map Engraving, Printing, and Coloring in the European Renaissance", en Woodward, D. (ed.), The History of Carto- graphy, vol. 3, Cartography in the European Renaissance, pp. $591-610$. University of Chicago Press.

\section{Mapas analizados y descritos en el texto}

Barents, W. y Hondius, J. (1595). Hydrographica descriptio maris Mediterranei à freto Gaditano, usque ad C. dictum, de Gates: in qua orae maritimae Hispaniae et Barbariae, portus item et promontoria, insulae, vada, Brevia, necnon loca in quibus tuto anchoras figere liceat, evidenter et summa diligentia designantur, a peritissimo nauclero Guilielmo Barensono. [ca. 1:930.000]. Amsterdam. Grabado, 33 x $55 \mathrm{~cm}$. En: Biblioteca Nacional de España.

Blaeu W.J. (1634). Andalvzia continens Sevillam et Cordvbam. [ca. 1:1.150.000]. Amsterdam. Grabado, $38 \times 50 \mathrm{~cm}$. En: Koninklijke Bibliotheek (La Haya).

Blaeu W.J. (1635). Granata, et Murcia Regna. [ca. 1:1.200.000] Amsterdam. Grabado, 38 X $50 \mathrm{~cm}$. En: Österreichische Nationalbibliothek (Viena).

Blaeu, J. (1646). Andaluzia: continens Sevillan et Cordubam. [ca. 1:1.333.000]. Amsterdam. Grabado, $38 \times 50 \mathrm{~cm}$. En: Cartoteca del IGN.

Bonne, R. (1762). L'Andalousie avec les Royaumes de Grenade et de Murcie. [ca. 1:1.913.793]. París. Grabado, 23 X 34 cm. En: Fundación Luis Giménez Lorente (Universidad Politécnica de Valencia)

Briet, P. (1649). La Castille Meridionale Avec Ses Dependences. Paris. Grabado, 15 x $20 \mathrm{~cm}$. En: Cartoteca Histórica Digital de Extremadura.

Cantelli, G. y De Rossi, D. (1696) Li regni di Granata é d'Andalucia, [ca. 1:624.375]. Roma. Grabado, 63 X $96 \mathrm{~cm}$. En: Biblioteca de Andalucía.

Cassini, G.M. (1794). L'Andalusia con i Regni di Granada e di Murcia. [ca. 1:1.310.000]. Roma. Grabado, 33 x 47,5 cm. En: Fundación Luis Giménez Lorente (Universidad Politécnica de Valencia).

Chaves, J. (1579). Hispalensis conventus delineatio. [ca. 1:640.000]. Amberes. Grabado, 35 x 43 cm. En: Cartoteca del IGN.

Da Cassino, G.B. y Durelli, S. (1712). Provincia Andalvsiae. [ca. 1:1.860.000]. Milán. Grabado, 22 x $33 \mathrm{~cm}$. En: Institut Cartogràfic i Geològic de Catalunya.

Danckerts, J. (1680). Regnum Castellae Novae, Andalusiae, Granadae et Algarbiae, nec non maxime partis Portugalliae... [ca. 1:1.150.000]. Amsterdam. Grabado, 45 x 55,5 cm. En: Cartoteca del IGN. 
De Fer, N. (1705). L'Andalousie, les royaumes de Grenade, et de Murcie et grande partie de ceux de Leon, de Castille, et de Valence. [ca. 1:1 780 000]. París. Grabado, 25 x $35 \mathrm{~cm}$. En: Institut Cartogràfic i Geològic de Catalunya

De Fer, N. (1707). Les Royaumes de Grenade et d'Andalousie. [ca. 1:450.000]. París. Grabado, 44 x $48 \mathrm{~cm}$. En: Cartoteca del IGN.

Du Val, P. (1688). L' Andalousie et le royaume de Grenade. [ca. 1:1.520.000]. París. Grabado, 40 x $52 \mathrm{~cm}$. En: Bibliothèque nationale de France.

Eguilart, P.A. (1770). Carta Geografica del Condado de Niebla Dedicada â su dueño el Excelentissimo Señor Don Pedro Alonso de Guzman el Bueno. [ca. 1:345.000]. [s.I.]. Manuscrito, $137 \mathrm{x}$ $117 \mathrm{~cm}$. En: Archivo Fundación Casa de Medina Sidonia.

Espelius, J.A. (1765). Mapa o carta corographica que comprehende todas las provincias de marina, que componen el departamento de Cadiz. [ca. 1:1.760.000]. [s.l.]. Manuscrito, 63 x $84 \mathrm{~cm}$. En: Biblioteca Nacional de España.

Espinalt y García, B. Cucó, P. (1795). Mapa del Reyno de Sevilla. [ca. 1:1.530.000]. Madrid. Grabado, 13 x $18 \mathrm{~cm}$. En: Cartoteca del IGN.

Flórez, E. y De La Peña, J. (1752). Betica antigua, con sus montes, rios i pueblos conocidos. [ca. 1:1.500.000]. Madrid. Grabado, 48 x $55 \mathrm{~cm}$. En: Biblioteca Nacional de España.

Heirs, H. (1730). Carte Nouvelle de l'Isle de Cadix \& du Detroit de Gibraltar. [ca. 1:495.000]. Nuremberg. Grabado, 58,5 x 49,5 cm. En: Bibliothèque nationale de France.

Hoffrichter, L.D. (1673). Descripción del obispado de Córdoba. [ca. 1:620.000]. Córdoba. Manuscrito sobre papel, 37 x $54 \mathrm{~cm}$. En: Biblioteca de la Catedral de Córdoba.

Hondius, J. (1606). Andaluziae nova descript. [ca.1:1.366.000]. Amsterdam. Grabado, 35,5 x 50 cm. En: Cartoteca del IGN.

Hondius, J. (1635). Andaluzia. [ca. 1:3.472.000]. Londres. Grabado, 13,5 x $23 \mathrm{~cm}$. En: Cartoteca del IGN.

Kremer, G. (1663). Granata et Murcia Regna. [ca. 1:1.150.800] Amsterdam. Grabado, 38 x $50 \mathrm{~cm}$. En: Fundación Luis Giménez Lorente (Universidad Politécnica de Valencia).
López, T. (1761). Mapa del Reyno de Cordova. [ca. 1:437.000]. Madrid. Grabado 42 x 45 cm. En: Centro Geográfico del Ejército.

López, T. (1767). Mapa del Reyno de Sevilla, dibidido en su Arzobispado, Obispado, y Tesorerías. [ca. 1:324.000]. Madrid. Grabado 78 x $77 \mathrm{~cm}$. En: Biblioteca de Andalucía.

López, T. (1797). Mapa Geográfico del Reino y Obispado de Córdoba. [ca. 1:250.000]. Madrid. Grabado, $63 \times 45 \mathrm{~cm}$. En: Biblioteca de Andalucía.

López, T. y Güssefeld, F.L. (1782). Granadae, Cordovae et Gienensis Regna. [ca. 1:645.000]. Nuremberg. Grabado, 45 x 58 cm. En: Institut Cartogràfic i Geològic de Catalunya.

Llobet, F. (1748). Mapa del Reynado de Sevilla... [ca. 1:1.200.000] [s.l.]. Grabado, 103 x 135 cm. En: Biblioteca Nacional de España.

Llobet, F., López, T. y Güssefeld, F.L. (1781). Sevilla Regnum in suos Archiepiscopatos Episcopatos et Praefecturas divisum. [ca. 1:625.000]. Nuremberg. Grabado, $42 \times 56 \mathrm{~cm}$. En: Cartoteca del IGN.

Metellus, J. y Lambert, A. (1595a). Andalusia. [ca. 1:2.800.000]. Colonia. Grabado, 14 x 24,5 cm. En: Biblioteca de la Universidad de Sevilla.

Metellus, J. y Lambert, A. (1595b). Granatae regnv[m]. [ca. 1:2.300.000]. Colonia. Grabado, 14 x 24,5 cm. En: Biblioteca de la Universidad de Sevilla.

Michelot, H. y Brémond, L. (1723). Carte Particuliere des Côtes D'Espagne et Barbarie, depuis Gibraltar jusqu'au Cap de Palle et depuis Ceuta jusqu'au Cap Ferat. [ca. 1:750.000]. París. Grabado, 48 x 69 cm. En: Institut Cartogràfic i Geològic de Catalunya.

Moll, H. (1712). Baetica or the southern Part of Spain. [ca. 1:2.900.000]. Londres. Grabado, 14 x $16 \mathrm{~cm}$. En: Biblioteca de Andalucía.

Moll, H. (1732). Baetica or the Southern Part of Spain as it is described by Caesar de Bello Hispanico. [ca. 1:2.900.000]. Londres. Grabado, 15 x $23 \mathrm{~cm}$. En: The Gennadius Library - The American School of Classical Studies at Athens

Nolin, J.B. (1720). Parte Meridional de las Costas d'España con los Reynos de Granada y Andalucia y poblaciones de los antiguos reynos de Cordüa, de Sevilla y Jaen. [ca. 1:685.000]. París. Grabado, 58 x $87 \mathrm{~cm}$. En: Institut Cartogràfic i Geològic de Catalunya. 
Roux, J. (1764). Carte de la Mer Mediterranée: en Douze Feuilles. [ca. 1:695.000]. Marsella. Grabado, 55 x $77 \mathrm{~cm}$. En: Cartoteca del IGN.

Salcedo de Aguirre, G. (1587). Geographia o description nueva del obispado de Jaen. [ca. 1:350.000]. Manuscrito, 41,5 x $58 \mathrm{~cm}$. En: Biblioteca Nacional de España.

Sanson d'Abbeville, N. y Sommer, I. (1652). Les Estats de la Couronne de Castille, dans les Parties Plus Meridionales de l'Espagne: et la ou sont. Castille Nouvelle, Andalousie, Grenade et Murcie. Grabado, 40,5 x 53,5 cm. En: Cartoteca del IGN.

Seutter, M. (1730). Accurata designatio celebris freti prope Andalusiae castellum Gibraltar inter Europam et Africam cum circumjacentibus portubus et castellis. [ca. 1:474.800]. Augsburgo. Grabado, 37 x $58 \mathrm{~cm}$. En: Biblioteca Nacional de España.

Texeira, P. (1634a). Tabla del Reyno de Andaluzia. [ca. 1:795.000]. Madrid. Manuscrito sobre vitela, 39 x $66 \mathrm{~cm}$. En: Österreichische Nationalbibliothek (Viena).

Texeira, P. (1634b). Reino de Granada. [ca. 1:520.000]. Madrid. Manuscrito sobre vitela, Grabado, 39×66 $\mathrm{cm}$. En: Österreichische Nationalbibliothek (Viena).

Vagoundy, R. (1751). Partie Meridionale des Etats de Castille, où se trouvent La Castille Nlle... [ca.
1:1.340.000]. París. Grabado, 48 x 55 cm. En: Cartoteca del IGN.

Van den Keere, P. (1632). Andaluzia. [ca. 1:2.700.000]. Amsterdam. Grabado, 18,5 x 25,5 cm. En: Instituto Geográfico Nacional.

Van den Keere, P. y Janssonius, J. (1628). Andalusia et Granada. [ca. 1:2.780.000]. Ámsterdam. Grabado, 14,5 x $20 \mathrm{~cm}$. En: Biblioteca Cánovas del Castillo.

Van der Aa, P. (1714). Nueva Mapa de Andalucía y Granada, con los caminos reales. [ca. 1:3.003.000]. Leiden. Grabado, 12,5 x $16 \mathrm{~cm}$. En: Cartoteca del IGN.

Van Doetichum, J. y Janszoon Waghenaer, L. (1583). Zee custen van Andaluzien gemacckt naet mesen en ghedaente, met zijn Rivieren een Hauenen. [ca. 1:423.300]. Leiden. Grabado, 33 x $51 \mathrm{~cm}$. En: Biblioteca Nacional de España.

Visscher, N. (1683). Regnorum Castellae Novae AndaIusiae Granadae Valentiae et Murciae Accurata Tabula. [ca. 1:1.220.000]. Amsterdam. Grabado, 54 x 84 cm. En: Cartoteca Histórica Digital de Extremadura.

Zatta, A. (1776). Andalusia e Granada: Di Novissima Projezione. [ca. 1:1.760.000]. Venecia. Grabado, 31 x $40 \mathrm{~cm}$. En: Cartoteca del IGN. 